\title{
Factors Predicting the Intention of Academics of Faculties of Agriculture in the State Universities in Sri Lanka to Engage in Outreach Activities
}

\author{
R.M.S. Wijerathna ${ }^{*}$, H.V.A. Wickramasuriya ${ }^{1}$ and B. Marambe ${ }^{2}$ \\ Postgraduate Institute of Agriculture \\ University of Peradeniya \\ Sri Lanka
}

\begin{abstract}
Evidence of research conducted on outreach activities of Faculties of Agriculture in the state Universities of Sri Lanka focusing on agriculture related knowledge transfer is meagre or absent. Therefore, the objective of this study was to investigate, with an underlying theoretical framework, the factors that would predict the intention (participation decision) of academia to engage in outreach activities. The theory of planned behaviour (TPB) was applied for the prediction. A structured questionnaire was e-mailed and posted to randomly selected 67 $\%$ of the academic staff members from each of the eight Faculties of Agriculture $(N=257)$ in the state Universities of Sri Lanka, where 126 filled questionnaires (49\%) were returned after three reminders. The results indicated that the application of the theory along with additional variables could explain $39 \%$ of the total variability. In general, satisfaction, recognition and rewards, subjective norms and positive attitudes towards outreach activities were the strongest predictors of intention to engage in outreach activities. Those who have engaged in outreach activities in the past with a higher general level of satisfaction are more likely to engage in outreach activities in future as well. These findings suggest that interventions to promote outreach activities of the academia of Faculties of Agriculture in the state Universities should target these factors in the short run together with establishment of an effective formal mechanism for outreach in the long run.
\end{abstract}

Keywords: Academics, Faculties of Agriculture, outreach, state universities, theory of planned behaviour

\section{INTRODUCTION}

Teaching and research are considered as key traditional functions of the universities. However, a third role has emerged as "the outreach" in many of the universities in the world. Scholars have highlighted the fact that higher agriculture education in Sri Lanka needs a massive renewal of intellectual life. The Faculties of Agriculture should proactively join the extension programmes in collaboration with the state organizations such as the Department of Agriculture, Department of Animal Production and Health, other private institutions and Non-Governmental Organizations (Gunasena, 2004). Therefore, engagement in outreach activities by academics is an important aspect. Unlike the basic sciences, agricultural education and research should emphasize more on practical applications and should contribute to the solution of agricultural and rural problems. If higher education in agriculture is designed and developed based on this focus, theoretically, Faculties of Agriculture should have more deliverable outputs for the agricultural

\footnotetext{
1 Department of Agricultural Extension, Faculty of Agriculture, University of Peradeniya, Sri Lanka

2 Department of Crop Science, Faculty of Agriculture, University of Peradeniya, Sri Lanka

Corresponding author: madhaviwijerathna@yahoo.com
} 
development of the country. The outreach, or extension, tasks refer to the more direct contribution of higher education in agriculture to agricultural and rural development. It may include educational programmes for communities beyond the university campus, the conduct of policy, industry and community-oriented research into issues identified by the consumers themselves, and offering various kinds of services to the community such as technical assistance and agricultural and rural planning (Van den Bor et al., 1989).

Academic staff of the universities is the key resource in teaching, research as well as in outreach activities. According to Crowder et al. (1998), agricultural education institutions play not only an academic role but also a community development or outreach role that allows them to understand local knowledge and combine it with modern agricultural science.

Recent interventions of the University Grants Commission (UGC) in Sri Lanka have paid more attention to improve the university-industry linkages, community-based learning and outreach activities. Despite this fairly new and growing interest of the Sri Lankan government, policy makers and educational specialists, only a few research studies have been conducted on the university-industry linkages to facilitate policy formulation in Sri Lanka (Esham, 2008). However, there is no evidence of research conducted on outreach activities of the Faculties of Agriculture in Sri Lanka focusing more on agriculture related knowledge transfer, education, communication and community/rural development. Moreover, theoretically designed research to identify the factors that affect the engagement on outreach activities by academics, which would be helpful in developing policy implications and designing guidelines and procedures to promote university outreach activities, is scanty. Therefore, the objective of this study was to investigate, with an underlying theoretical framework, the factors that would predict the intention of academics of the Faculties of Agriculture in the state Universities of Sri Lanka to engage in outreach activities. The theory of planned behaviour (TPB) was applied for the prediction.

The working definition for outreach activities in this study was, "the process of active participation with the government and nongovernmental organizations, industry and community to share the university academic's knowledge, experience, expertise and resources to address the needs and problems faced". The educational programmes, trainings, workshops, consultancies, development projects, communication and related activities were taken as the outreach activities.

\section{The Theory of Planned Behaviour (TPB)}

The TPB (Fig. 1) has been developed in the discipline of social psychology to determine the intention of individuals to perform a particular behaviour. More than 490 studies have been conducted applying and refining this theory in explaining different kinds of social behaviour (Conner and Sparks, 2005). There are more than 27,000 citations for the research paper introducing the theory by Ajzen (1991). It is an accepted fact that human behaviour is complex and difficult to explain. However, social and psychological theories and models have been developed by scholars to allow better understanding of behaviour. The intentions-centred TPB of Ajzen (1991) is parsimonious, well grounded in theory, and robustly predicts a wide variety of planned behaviour (Norris and Alan, 1993). The theory states that the intentions to perform behaviours of different kinds that can be predicted with high accuracy from are (i) attitude toward the behaviour, (ii) subjective norms and (iii) perceived behavioural control, These intentions together with the perceptions of behavioural control, account for considerable variance in actual behaviour. The central factor in the theory is the "individual's intention to perform a given behaviour" (Ajzen, 1991). 


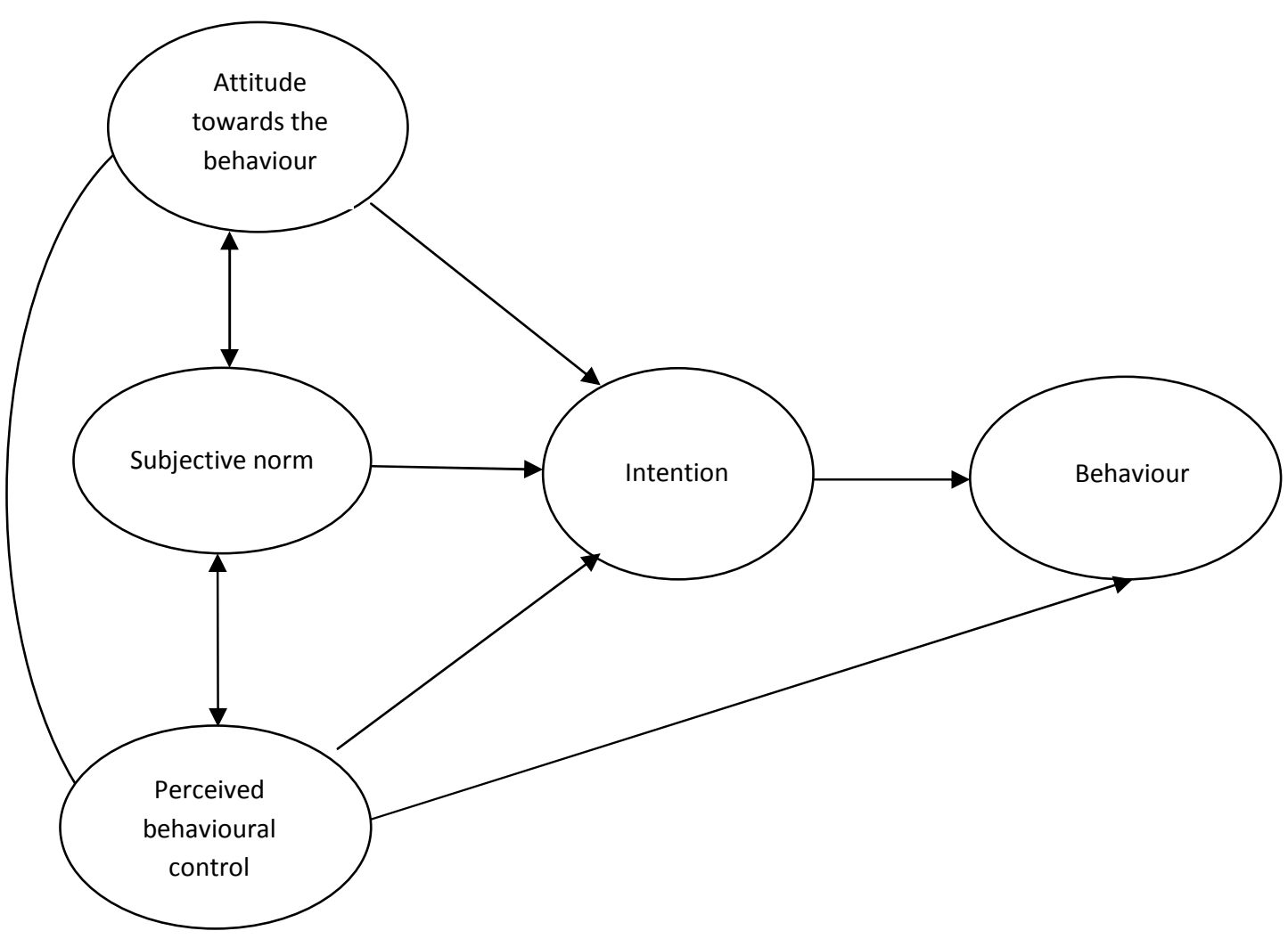

Fig. 1. Theory of planned behaviour (Ajzen, 1991)

\section{METHODOLOGY}

\section{Participants and design}

All the Faculties of Agriculture (8) in the state Universities of Sri Lanka offering agriculture and related degrees were selected for the study. A structured questionnaire was e-mailed and posted to randomly selected academic staff members of each faculty $(67 \% ; \mathrm{N}=257)$. As a result, 126 filled questionnaires $(49 \%)$ were returned after three reminders. Two questionnaires were not used due to incompleteness.

\section{Measures}

Questionnaire measures were taken from the constructs built based on the TPB. A five-point Likert scale $(1=$ strongly agree, $2=$ agree, $3=$ neutral, $4=$ disagree, $5=$ strongly disagree $)$ was adapted to measure attitude, subjective norm, behavioural constraint and intention variables.

\section{i) Attitude towards the behaviour}

Attitude towards the behaviour was measured by four statements namely; "My belief is outreach is not a mission of the university", "I have a duty as an academic/scientist to engage in outreach 
activities", “Engaging in outreach activities is enjoyable" and "Engaging in outreach activities is beneficial" (Cronbach's alpha $=0.70)$.

\section{ii) Subjective norms}

Subjective norms are the beliefs about whether a specific reference group would approve or disapprove a particular behaviour. Those were measured using three items namely, "My academic colleagues would approve the engagement in outreach activities", "My superiors (e.g.: Head of the Department/Dean of the Faculty) would approve the engagement in outreach activities" and "My friends (non academic and family members) would approve the participation in knowledge and technology dissemination" (Cronbach's alpha $=0.78$ ).

\section{iii) Perceived behavioural control}

According to the TPB (Ajzen 1991), the perceived behavioural control refers to people's perception of the ease or difficulty of performing the behaviour. The ability to perform the task, availability of resources and opportunities are important considerations. Measures were taken from 11 items capturing the ability to engage in outreach activities and various possible limitations and constraints leading to the particular behaviour. The variables were "I have necessary knowledge and skills to engage in outreach activities", "There is no central mechanism/office to provide support and coordination", "Lack of established networks with government, private sector and community", "The University structure is not adopted for outreach activities", "University norms, culture and procedures do not support outreach activities", "Inadequate infrastructure facilities for outreach activities", "Geographical location of the university does not support outreach activities", "I am not aware about the opportunities to engage with outreach activities", "The University does not have a policy towards outreach activities", "There is no time for outreach activities due to heavy workload of teaching, research, administrative and other work" (Cronbach's alpha=0.76).

\section{iv) Intention to participate:}

Intention refers to the decision to engage in outreach activities. Intention was measured by the item "I intend to engage in outreach activities during next 12 months".

\section{Extension to the TPB}

Some authors have suggested that the TPB may effectively be supplemented by additional constructs. For instance, Poliakoff and Webb (2007) have used descriptive norms, moral norms, fear, recognition and the past behaviour as additional constructs in predicting scientists' intention to participate in public engagement of science activities. The present study also used recognition and rewards, past behaviour, satisfaction, gender, experience, discipline, educational qualification (having a Ph.D. vs. not having) and country of obtaining the higher educational qualification (local vs. foreign) as additional measurements to the theory.

Recognition and rewards was measured by using the item "I engage in outreach activities due to recognition and rewards". The general level of satisfaction was measured using five point Likert scale as highly satisfied, satisfied, neutral, dissatisfied and highly dissatisfied. The number of outreach activities done during the past two years was taken as the past behaviour. 


\section{Data analysis}

Descriptive statistical analysis (percentages and median) was used to summarize the data and explain the basic information. Correlation analysis (Table 1) was carried out to examine the associations between study variables. Hierarchical multiple regression was performed to predict the intention to engage in outreach activities using TPB constructs and additional variables (Table 2). The independent variables were entered in two blocks. The TPB variables (attitudes, subjective norms, and perceived behavioural control) were entered in the first step in order to see the utility of the theory in predicting intention. The additional variables to the theory (past behaviour, recognition and rewards, type of the university, discipline, satisfaction, gender, level of education, country of the higher educational qualification obtained and the experience as a university academic) were entered first and non-significant variables (type of the university, discipline, gender, country of the qualification obtained and experience) were discarded according to the Barron and Kenny procedure.

\section{RESULTS AND DISCUSSION}

\section{Descriptive statistics}

The sample of respondents adequately represented all levels of academics i.e. Professors (20\%), Senior Lecturers $(55 \%)$ and Lecturers $(25 \%)$. Among the respondents, 56\% were males and 44 $\%$ were females.

Academics generally perceived that they had the necessary knowledge and skills to engage in outreach activities having a Median (M) score of 2 (agree) for the said variable. Not having a central mechanism, lack of an established network, inadequate infrastructure facilities were the perceived constraints. They were neutral $(\mathrm{M}=3)$ in response for lack of autonomy, not having a policy towards outreach activities, time constraint and satisfaction. However, they were generally in the category of "agree" $(\mathrm{M}=2)$ to engage in outreach activities during the next 12 months.

\section{Correlations of the variables}

All constructed composite variables of the theory i.e. attitude towards the behaviour, subjective norms, and perceived behavioural control had significant positive correlations with the intention to engage in outreach activities (Table 1), with attitude having the strongest correlation. The intention was positively correlated with some additional variables namely, past behaviour, general level of satisfaction and recognition. Furthermore, attitude had a positive correlation with subjective norms, past behaviour, satisfaction and recognition but not with behavioural control, as the theory implies.

The experience as a university lecturer, university (established $v s$. newly established), educational qualification (having a Ph.D. vs. not having), country of the higher qualification obtained (local vs. foreign), gender and discipline had no significant correlations with the intention. 
Wijerathna et al.

Table 1. Correlations between the study variables

\begin{tabular}{|c|c|c|c|c|c|c|c|c|c|c|c|c|c|}
\hline Variable (V) & V1 & $\mathbf{V 2}$ & V3 & V4 & V5 & V6 & V7 & V8 & V9 & V10 & V11 & V12 & V13 \\
\hline \multicolumn{14}{|l|}{ V1 Intention } \\
\hline V2 Attitudes & $.46^{* *}$ & & & & & & & & & & & & \\
\hline V3 Subjective norms & $.37 * *$ & $.25^{* *}$ & & & & & & & & & & & \\
\hline V4 Behavioural controls & $.18^{*}$ & .11 & .04 & & & & & & & & & & \\
\hline V5 Past behaviour & $.41^{* *}$ & $.25^{* *}$ & .13 & .04 & & & & & & & & & \\
\hline V6 Satisfaction & $.38^{* *}$ & $.26^{* *}$ & .16 & $.25^{* *}$ & $.41 * *$ & & & & & & & & \\
\hline V7 Experience & .06 & -.11 & -.02 & -.08 & $.31 * *$ & .19 & & & & & & & \\
\hline V8 Recognition & $.33^{* *}$ & $.33 * *$ & .14 & .42 & -.04 & $.22 *$ & -.04 & & & & & & \\
\hline V9 University & .13 & .17 & -.04 & -.01 & $.19 *$ & $-.28 *$ & $.42 * *$ & .04 & & & & & \\
\hline V10 Discipline & .03 & -.04 & -.02 & -.21 & .04 & -.03 & .10 & -.17 & -.03 & & & & \\
\hline V11 Gender & .02 & -.13 & -.08 & .05 & $.27^{* *}$ & $.27 * *$ & $.20 *$ & .08 & .04 & .01 & & & \\
\hline V12 Edu. qualification & -.00 & -.02 & -.12 & -.10 & -.10 & -.08 & -.04 & .01 & -.13 & -.02 & -.14 & & \\
\hline V13 Country & .02 & -.13 & -.08 & -.01 & .03 & -.01 & $.51 * *$ & -.01 & -.20 & -.00 & .06 & .07 & \\
\hline
\end{tabular}

$* p<.05, \quad * * p<.01$ 


\section{Regression analysis}

At step 1 (Table 2), only the TPB variables namely, subjective norm, attitude and behavioural control were considered and the subjective norm was the significant predictor on intention to engage in outreach activities $(\beta=0.13, p<0.001)$ followed by attitude $(\beta=0.12$, $\mathrm{p}<0.001)$. As the theory has explained, there was no effect of the behavioural control $(B=$ $0.01, p>0.05)$. However, in the present study, $26 \%$ of the total variability could be explained using the TPB variables.

At step 2 (Table 2), the TPB variables were considered with additional variables. Satisfaction $(B=0.19)$, and recognition and rewards $(B=0.15)$ were the significant factors that predicted intention. The additional variables used at the second step accounted for a significant increase in the variance explaining the differences in intention $\left(R^{2}\right.$ change $=0.13$, $F$ change $=8.3, \mathrm{p}<0.001)$. Accordingly, the total variability that could be explained by applying the TPB along with additional variables was $39 \%$.

Table 2. Hierarchical multiple regression of outreach intention on putative predictors

\begin{tabular}{llll}
\hline Step & Variable entered & B (step 1) & B (step 2) \\
\hline 1 & Subjective norm & 0.13 & 0.11 \\
& Attitude & 0.12 & 0.08 \\
& Behavioural control & 0.01 & 0.01 \\
& & & \\
& Satisfaction & & 0.19 \\
& Recognition and rewards & & 0.15 \\
& Past behaviour & & 0.01 \\
& & \\
$R^{2}$ & 0.26 & 0.39 \\
$R^{2}$ change & 0.26 & 0.13 \\
& $F$ change & 13.7 & 8.3 \\
& Model $F$ & 13.7 & 12.3 \\
\hline
\end{tabular}

Similar to the results reported in the present study, Poliakoff and Webb (2007) reported that four factors namely, past behaviour, attitude, perceived behavioural control and descriptive norms are important determinants in scientists' intentions to participate in public engagement of science activities. Attitudes, subjective norms and past behaviour were also reported by Pliakoff and Webb (2007) as determinants to engage in outreach activities by academics together with additional measurements namely, satisfaction, past behaviour, recognition and rewards. The Royal Society (2006) report also identified reward and recognition for public engagement in work of the scientists as more effective in their decision making to be involved in such activities. In contrast to the TPB, in the present study, the behavioural control was not a significant determinant of intention. Breslin et al. (2001), in a study that applied the TPB for science communication reported that $56 \%$ of the variability of intention was explained by attitudes and subjective norms, and $19 \%$ of the variability was explained by behavioural control suggesting that perceived behavioural control was a significant predictor of actual behaviour but not intention.

Academics are generally confident enough in their competencies, while resources and opportunities available in their faculties were not of much importance to control their 
behavioural decision to engage in outreach activities. This may be due to two reasons, (1) the academics use their knowledge and expertise for outreach activities thus, the resources available in faculties may not be the main determinant on engagement decision, and (2) the majority $(60 \%)$ used the personal or informal contacts as the first means to coordinate their outreach activities thus, the formal outreach mechanism of universities may not be a main limitation. However, $55 \%$ of the academics suggested that it would be beneficial to have a formal outreach mechanism in the Faculties of Agriculture in order to promote outreach activities. Furthermore, the present study depicted that the academic support, freedom and their self-determination towards engaging in outreach activities being subjective norms, are the strongest predictors on intention to engage in outreach activities. Having a strong positive attitude towards the behaviour is another important determinant.

\section{CONCLUSIONS}

This study represents an application of theory of planned behaviour (TPB) to understand the factors that predict the engagement of academics of Faculties of Agriculture in the state Universities of Sri Lanka in outreach activities. Application of the theory along with additional variables could explain $39 \%$ of the total variability. In general, satisfaction, recognition and rewards, subjective norms and positive attitudes towards outreach activities were the strongest predictors of intention to engage in outreach activities. Those who have engaged in outreach activities in the past with higher general level of satisfaction are more likely to engage in outreach activities in future as well. The findings of the study suggest that the interventions to promote outreach activities of the academics of Faculties of Agriculture in the state Universities of Sri Lanka should target to increase the general level of satisfaction of the academia about outreach activities. There should be a mechanism for recognition and rewards. Promotion of attitudes and subjective norms would be short term implications. Establishment of an effective outreach mechanism should be a long- run implementation.

\section{REFERENCES}

Ajzen, I. (1991). The Theory of Planned Behaviour. Organizational Behaviour and Human Decision Process, 50, 179 - 211.

Breslin, B., Li, S., Tupker, E. and Jarvie, K.S. (2001). Application of the Theory of Planned Behaviour to Predict Research Dissemination: A prospective Study among Addiction Counsellors. Science Communication, 22, 4423 - 4437.

Conner, M. and Sparks, P. (2005). Theory of Planned behaviour and Health Behaviour: In: M. Conner \& P. Norman (Eds) predicting health behaviour ( $2^{\text {nd }}$ ed., pp.170-222) Buckingham,UK: Open University Press.

Crowder, L.V., Lindley, W.I., Bruening, T.H. and Doron, N. (1998). Agricultural Education for Sustainable Rural Development. Challenges for Developing Countries in the $21^{\text {st }}$ Century. Journal of Agricultural Education and Extension, 5, 71 - 84.

Esham, M. (2008). Strategies to Develop University-Industry Linkages in Sri Lanka. Study series No: 4 National Education Commission. 
Gunasena, H.P.M. (2004). Employment Potential of Agriculture and Veterinary Science Graduates, pp 1-14. In: Gunasena, H.P.M. (Ed.) Proceedings of the Seminar organized by the Standing Committee on Agriculture, Veterinary Medicine and Animal Science, University Grants Commission, Colombo.

Norris, F.K., and Alan, L.C. (1993). Entrepreneurial intentions: Applying the Theory of Planned Behaviour. Entrepreneurship and Regional Development, 5, 315 - 330.

Poliakoff, E. and Webb, T.L. (2007). What Factors Predict Scientists' Intentions to Participate in Public Engagement of Science Activities? Science Communication, 29, 242 263.

Royal Society. (2006). Survey of Factors affecting Science Communication by Scientists and Engineers. Final Report. London.

Van den Bor W., Shute J.C.M. and Moore, G.A.B. (Ed) (1989). South-North Partnership in Strengthening Higher Education in Agriculture, Centre for Agricultural Publishing and Documentation (PUDOC), Wageningen, Netherlands, p 25. 